\title{
Sistem Pendataan Barang Milik Negara dengan Secured $Q R$ Code dan REST API
}

\author{
Maidel Fani ${ }^{1 *}$, Nelmiawati ${ }^{2 *}$, Ahmad Hamim Thohari ${ }^{3 * *}$ \\ * Rekayasa Keamanan Siber, Politeknik Negeri Batam \\ ** Teknik Informatika, Politeknik Negeri Batam \\ maidelfani@polibatam.ac.id ${ }^{1}, \underline{\text { mia@polibatam.ac.id }}{ }^{2}, \underline{\text { hamim@polibatam.ac.id }}^{3}$
}

\begin{tabular}{l}
\hline Article Info \\
\hline Article history: \\
Received 16-03-2021 \\
Revised 25-06-2021 \\
Accepted 29-06-2021 \\
\hline
\end{tabular}

Keyword:

Barang Milik Negara, Secure QR Code, REST API

\begin{abstract}
Barang Milik Negara (BMN) adalah semua barang yang dibeli atau diperoleh atas beban Anggaran Pendapatan dan Belanja Negara (APBN) atau berasal dari perolehan lainnya yang sah. Politeknik Negeri Batam sebagai institusi pemerintah, wajib mengelola, memanfaatkan dan merawat BMN dengan baik agar didapat manfaat yang maksimal dari barang tersebut. Pemanfaatan teknologi mutlak diperlukan dalam rangka meningkatkan tata kelola dalam mengelola barang milik negara. Saat ini pengelolaan barang milik negara dilakukan dengan memberikan label yang berisi nomor pada setiap barang. Kendala yang muncul antara lain dalam proses pendataan, pelacakan dan pengelolaan barang milik negara, karena label tersebut dapat rusak, pudar dan terlepas. Penelitian ini mengusulkan aplikasi mobile dengan $Q R$ Code scanner untuk mengakses dan memeriksa data BMN dengan tepat. Aplikasi dilengkapi dengan secure $Q R$ Code generator dan REST API sebagai penyedia data $\mathrm{BMN}$.
\end{abstract}

This is an open access article under the $\mathrm{CC}-\mathrm{BY}-\mathrm{SA}$ license.

\section{Pendahuluan}

Barang Milik Negara (BMN) menurut PP 27 Tahun 2014 merupakan semua barang yang dibeli atau diperoleh atas beban Anggaran Pendapatan dan Belanja Negara (APBN) atau berasal dari perolehan lainnya yang sah. Politeknik Negeri Batam (Polibatam) sebagai satuan kerja dibawah Kementerian Pendidikan dan Kebudayaan (KEMENDIKBUD) wajib mengelola, memanfaatkan serta merawat $\mathrm{BMN}$ dengan baik agar didapat manfaat yang maksimal dari barang tersebut.

Pemanfaatan teknologi mutlak diperlukan dalam rangka meningkatkan efisiensi, efektifitas dalam mengelola BMN. Saat ini pengelolaan BMN dilakukan dengan memberikan label yang berisi nomor pada setiap barang. Hal ini kemudian menyulitkan dalam proses pendataan, pelacakan dan pengelolaan BMN, karena label tersebut dapat rusak, pudar dan terlepas. Disamping itu kesukaran dalam mengakses data terkait barang tersebut menjadi isu lain yang muncul.

Quick Response Code ( $Q R$ Code) adalah kode yang dapat dibaca mesin, berisi array dari kotak hitam dan putih yang merepresentasikan informasi maupun link yang dapat dibaca kamera smartphone. $Q R$ Code telah banyak digunakan untuk mendata alat dan bahan pada laboratorium IPA [1], optimasi aplikasi pengelolaan BMN [2] dan pemberian label dokumen oleh [3].

Penelitian ini mengusulkan aplikasi mobile dengan Secure $Q R$ Code untuk mengakses dan memeriksa data BMN dengan tepat. Aplikasi dibuat pada platform Android sehingga diharapkan proses pendataan dan pemantauan BMN akan lebih fleksibel dengan menggunakan perangkat mobile. Aplikasi yang dibangun juga dilengkapi dengan REST API sebagai penyedia layanan data BMN. REST Applications Programming Interface (API) Web Service merupakan salah satu bentuk perkembangan teknologi yang digunakan untuk integrasi sistem yang dapat dibangun dengan platform yang berbeda-beda maupun sistem operasi yang berbeda-beda [4]. Aplikasi BMN ini nantinya akan diakses melalui web dan juga mobile sehingga dengan pemanfaatan REST API akan memudahkan dan membuat lebih efektif dan efisien

Keamanan terhadap asset BMN juga merupakan satu faktor penting yang perlu dijaga. Penelitian ini menambahkan sebuah digital signature terhadap informasi yang akan ditambahkan pada $Q R$ Code. Dengan begitu, identitas BMN Polibatam tetap terjaga dengan baik dan dapat menunjukkan keasliannya. 


\section{LANDASAN TEORI}

\section{A. QR Code}

$Q R$ Code merupakan bentuk pengembangan kode batang (barcode) oleh Denso Wave, sebuah perusahaan Jepang pada tahun 1994. Dengan membawa kelebihan mudah dibaca dan dapat memberikan respon yang cepat. Selain itu, $Q R$ Code dipercaya mampu menyimpan data yang lebih besar daripada kode batang sebelumnya [5].

\section{B. Digital Signature}

Digital signature merupakan salah satu teknologi yang dapat digunakan untuk meningkatkan keamanan pada sebuah aset. Dengan adanya digital signature, dapat memastikan bahwa informasi yang ada merupakan informasi yang sebenarnya. Sehingga, ia dapat menjamin dua syarat keamanan informasi yaitu dari segi autentikasi dan penyangkalan.

Keamanan informasi yang diperoleh dari digital signature yaitu dengan memanfaatkan dua buah kunci, yaitu kunci publik dan pribadi. Dimana kunci publik digunakan untuk mengenkripsi data, sementara kunci pribadi digunakan untuk mendekripsi data tersebut. Data yang akan diamankan akan diberi fungsi hash terlebih dahulu sehingga menghasilkan yang namanya Message Digest. Kemudian message digest dienkrip oleh kunci publik menghasilkan digital signature [6].

\section{Barang Milik Negara (BMN)}

BMN yang dimaksud menurut PP 27 tahun 2014 yaitu semua barang yang dibeli atau diperoleh atas beban Anggaran Pendapatan dan Belanja Negara atau berasal dari perolehan lainnya yang sah. Barang sebagaimana dimaksud pada ayat (1) huruf b meliputi: barang yang diperoleh dari hibah/sumbangan atau yang sejenis; barang yang diperoleh sebagai pelaksanaan dari perjanjian/kontrak; barang yang diperoleh sesuai dengan ketentuan peraturan perundangundangan; atau barang yang diperoleh berdasarkan putusan pengadilan yang telah berkekuatan hukum tetap. Kewenangan dan tanggung jawab pengelola BMN adalah melakukan pembinaan, pengawasan dan pengendalian atas pengelolaan Barang Milik Negara. BMN yang ada di Polibatam menjadi tanggung jawab dan kewenangan dalam mengelolanya. BMN yang ada meliputi meja dan kursi dosen, ruang kelas, peralatan praktikum, dan lain sebagainya [7].

\section{REST API}

Salah satu jenis dari Web Service adalah REST atau RESTful (Representational State Transfer). REST memungkinkan system request dapat mengakses dan memanipulasi teks yang direpresentasikan dari sebuah layanan Web. Web Service API yang menggunakan REST disebut dengan RESTful API. Dalam penggunaannya, REST API terbukti lebih cepat dalam transfer data dari pada metode lain yang serupa, dalam hal ini SOAP (Symple Object Access Protocol) [8].

\section{E. Algoritma MD5}

Algoritma MD5 merupakan fungsi hash satu arah yang dibuat oleh Ron Rivest, MD5 adalah penyempurnaan dari MD4. MD5 ini sangat peka terhadap perubahan pesan, sehingga jika terjadi perubahan dengan jumlah sedikit akan dapat dideteksi [10]. Keluaran dari MD5 adalah 4 blok dengan total 128 bit yang disebut dengan nilai hash [12]

\section{METOde PENELITIAN}

Metode penelitian yang digunakan dalam membangun aplikasi ini yaitu metode protoyping. Metode prototyping merupakan sebuah metode pengembangan sistem dimana sebuah purwarupa dari suatu sistem dibangun, diujikan, dan dibangun kembali sehingga terbentuklah sebuah purwarupa akhir yang dapat diterima sesuai dengan yang tujuan penelitian yang akan dicapai. Purwarupa yang akan dicapai pada penelitian kali ini yaitu berupa sebuah $Q R$ Code yang dapat menyimpan informasi digital signature untuk BMN Polibatam. Purwarupa $Q R$ Code ini nantinya diharapkan dapat dibaca oleh smartphone dan dapat dijadikan sebuah alat untuk mengakses informasi terkait barang-barang BMN yang ada di Polibatam.

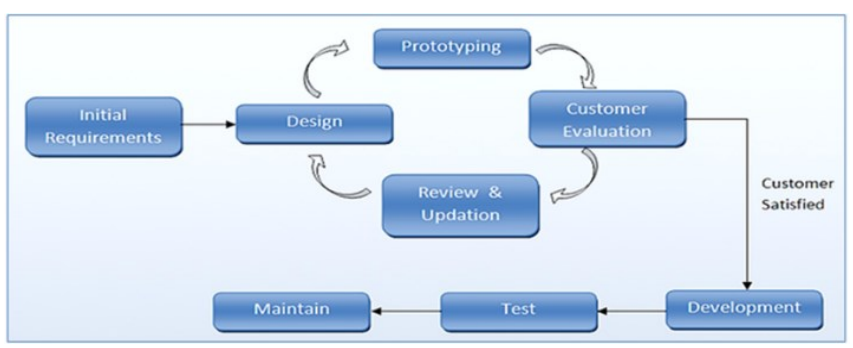

Gambar 1. Prototyping [9]

Adapun beberapa tahapan dalam penelitian ini adalah sebagai berikut:

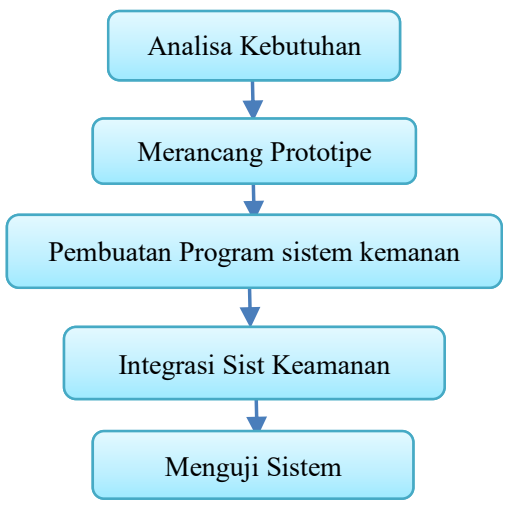

Gambar 2. Diagram Tahapan Penelitian 
45

\section{A. Analisa Kebutuhan}

Analisa kebutuhan sistem meliputi tiga tahapan:

\section{1) Studi Literatur}

Pengumpulan data dilakukan dengan cara mempelajari, meneliti dan menelaah berbagai literatur yang bersumber dari jurnal ilmiah, situs internet dan bacaan lainnya yang berkaitan dengan penelitian yang di lakukan. Pada tahap ini, peneliti memerlukan studi literatur mengenai pembuatan $Q R$ Code [11], pengkodean, algoritma digital signature yang akan digunakan, dan data-data apa saja yang akan diletakkan kedalam $Q R$ Code sendiri dan juga bentuk data yang bisa diletakkan.

\section{2) Analisa Data}

Menganalisa data-data yang sudah terkumpul agar dapat dilihat fungsionalitas yang diinginkan pengguna. Pada tahap ini peneliti akan mencari dan menganalisa informasi tentang BMN yang ada di Polibatam sebagai bahan pokok yang akan digunakan pada saat pembuatan $Q R$ Code dan aplikasi BMN berbasis android.

\section{3) Wawancara}

Wawancara dilakukan kepada kepala Urusan BMN Politeknik Negeri Batam. Dari wawancara diperoleh informasi, prosedur dan borang standar yang digunakan dalam proses bisnis pengelolaan barang milik Negara di Politeknik Negeri Batam. Selain itu kendala yang dihadapi dalam pengelolaan data, terutama pelacakan lokasi barang.

\section{B. Merancang Prototipe}

Merancang prototype dengan membuat perancangan desain produk sementara dengan alur tertentu yang berfokus pada penyajian desain sistem model awal aplikasi secara umum. Pada tahap ini, peneliti merancang purwarupa $Q R$ Code dan juga merancang aplikasi berbasis android yang akan dibuat.

\section{Pembuatan Program Sistem Keamanan}

Dalam tahap ini desain yang telah disepakati akan diterjemahkan ke dalam bahasa pemrograman dengan menggunakan platform android studio, dengan menghasilkan sebuah API $Q R$ Code generator yang sudah dilengkapi fitur keamanan digital signature. Untuk proses hash menggungakan library Angular-MD5, proses enkripsi menggunakan library JSEncrypt, dan proses dekripsi menggunakan library JSEncrypt.

\section{Integrasi Sistem Keamanan}

Proses integrasi sistem keamanan dilakukan dengan website dan aplikasi mobile yang ada.

\section{E. Menguji Sistem}

Setelah berhasil terbentuknya sebuah API, peneliti akan menguji sistem tersebut dengan mengintegrasikan dengan aplikasi mobile untuk membaca $Q R$ Code yang telah dibuat. Selanjutnya peneliti akan mencoba untuk menguji apakah $Q R$ Code yang dibaca oleh aplikasi dapat menampilkan informasi berupa website yang telah dibuat oleh peneliti selanjutnya. Metode pengujian yang akan dilakukan terhadap penelitian kali ini yaitu dengan menggunakan metode black box. Pengujian ini memastikan bahwa purwarupa yang dibuat telah sesuai dengan perancangan desain, dapat beroperasi dengan baik dan dapat digunakan secara terus menerus dalam jangka waktu panjang untuk pengembangan dan penelitian selanjutnya.

\section{Hasil dan Pembahasan}

\section{A. Prototipe Aplikasi BMN}

Hasil penelitian ini adalah prototipe aplikasi mobile dengan memanfaatkan $Q R$ Code scanner untuk mengakses dan memeriksa data barang milik negara secara cepat dan akurat. Pada $Q R$ Code juga ditambahkan digital signature untuk menjaga kemanan data BMN dan juga untuk menunjukkan keasliannya.

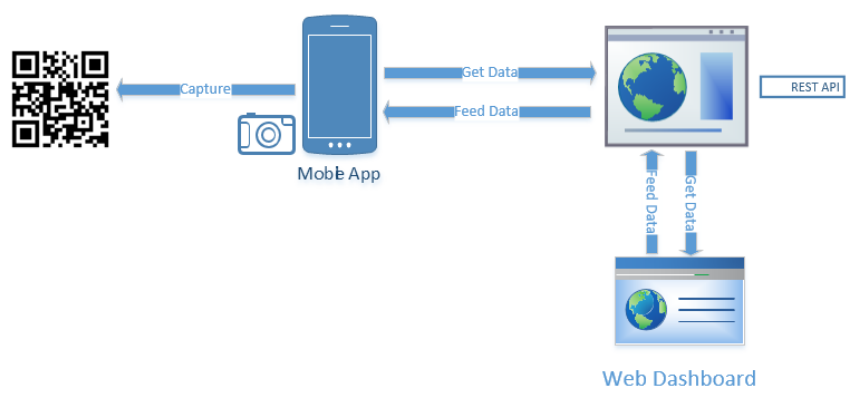

Gambar 3. Deskripsi umum sistem

Pada Gambar 2 ditampilkan bagaimana proses pengelolaan data barang milik negara di aplikasi. Aplikasi mendapatkan data di REST API dan mencocokkan dengan $Q R$ Code yang terdapat pada barang milik negara. Web Dashboard merupakan laman manajemen data barang milik negara yang dikelola bagian terkait.

\section{1.) REST API}

Pada desain ini setelah kamera berhasil membaca $Q R$ Code yang merupakan label inventaris, aplikasi akan mencocokkan data dengan database yang ada di server melalui REST API. Sehingga setelah dilakukan scan $Q R$ Code aplikasi mobile dapat menampilkan data terkait inventaris tersebut.

Dengan adanya REST API ini sangat membantu untuk dikembangkan di platform yang berbeda-beda. REST API dalam mengelola BMN terdiri dari REST API Tabel user, REST API Tabel barang, REST API Kategori barang, RST API Ruangan. 


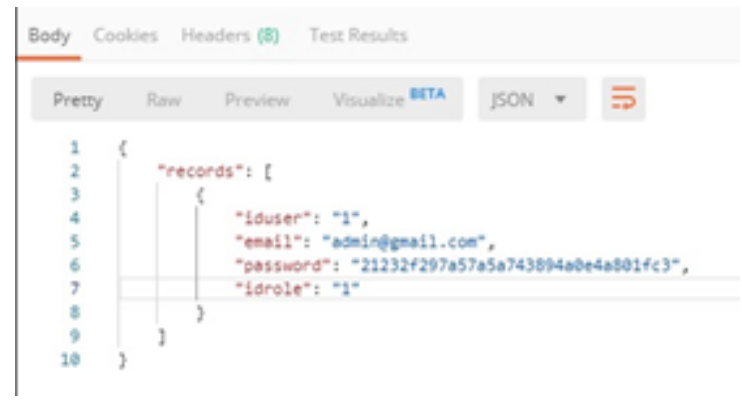

Gambar 4. REST API Tabel User

2.) Implementasi $Q R$ Code Reader pada Aplikasi Mobile

Impelementasi $Q R$ Code reader digunakan dengan mengunakan library ZXING (Zebra Crossing) yang merupakan library yang cukup popular dalam pembuatan program pembacaan barcode dengan $Q R$ Code. Aplikasi $Q R$ Code scanner berfungsi untuk melakukan pendataan BMN secara cepat dan akurat.

Aplikasi BMN ini dikembangkan berbasis javascript dengan framework React, dan memanfaatkan database firebase dari google.
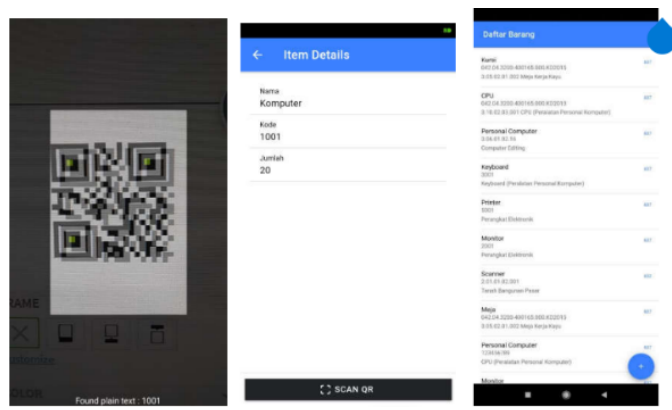

Gambar 5. Mobile App aplikasi BMN

Sebelum pembuatan prototipe aplikasi mobile BMN terlebih dahulu sudah melakukan perancangan, pemodelan data dan analisis fungsionalitas sesuai kebutuhan di Polibatam. Pengguna dari aplikasi mobile BMN ini adalah karyawan Polibatam.

\section{B. Digital Signature pada $Q R$ Code}

Terdapat 3 proses yang berlangsung dalam purwarupa secured API QR Code generator

\section{1.) Key generator}

Kunci publik dan kunci pribadi dibuat tetap untuk melakukan enkripsi dan deskripsi Polibatam seperti pada Gambar 5 dan Gambar 6.
MIICXQIBAAKBgQDObZtjxfplZYRgo6TKZM9E6b3RVQpXTpKTOiqefTKEp T9//ru1 x0rHgqpsjcw1BoXFX3SuYRPn3ijCM/C9WHnc2PDjEgGu0KezIxvqE7n CjbHed7pff6fov6ZajFsiwcf2r3oOwCjWMW1ChHP0ZYF2AilHmInarJutHTwEElb3QIDAQABAoGAHLkVmRFwIPG6NLQwdtUGHiGj/t+lW7acII5EZd8ny1s u9cFdHxMG7bHZwtcMJgitTmRU2Pq7CVVZOIR/p+kKs5cPE6gH5UGIYi0MT ZV3sD4hSWMRs+baNiRkaWLECOxk0o4Xe80StheoL89K2dIwFrc28BAowdvr HHjeqvYRsgECQQDymDTCXjoHGAhGT77gnAVmOY9QsB00mieVxC06LH wC1TfM51k8QgalUDIp/pxaCZp5F014Uy2Tzg+Bphr2+OVdAkEA2dXIh0rSJM8 zw312MJT5YFwNkDpgmMN/aN1FPAVHtLVoMn8d7p8pw7DUEQ5sl+Sk5Xw WWa9AEckkG3SRW3BogQJBAL5Flwvj78tklAjhvypX9PwqpTd6Ck4YXC+hQ H/iKBnotelmftz+REwgzFeXtXYBFkFnfF59jr/g3NSpPXj72pkCQCanLZ78Is/PS IMexxMVZC5SB0IZabyRrBECel+NHE0vh162eaw25+VGgkrIgXJuaughnaGqX DcLtvF8PLK5/oECQQDkQ1/IAPBbI5QXLmfiseu7duRtZ9px/7HYDOEDtjiasOy BGW2M17FYxYTPJX6uIhxflpX1Bt1Kdtue3Wu3OMRC

Gambar 5. Kunci Pribadi

MIGAMA0GCSqGSIb3DQEBAQUAA4GNADCBiQKBgQDObZtjxfplZYRgo6T KZM9E6b3RVQpXTpKTOiqefTKEpT9//rulx0rHgqpsjcw1BoXFX3SuYRPn3ij CM/C9WHnc2PDjEgGu0KezIxvqE7nCjbHed7pff6fov6ZajFsiwcf2r3oOwCjWM W1ChHP0ZYF2Ai1HmInarJutHTwE+Elb3QIDAQAB

Gambar 6. Public key

\section{2.) Signature}

Signature merupakan pesan dimana pada penelitian ini berupa kode item data BMN Polibatam akan di hash dengan menggunakan MD-5(H)M)), 128 bits. Nilai hash yang dihasilkan kemudian dienkripsi dengan kunci pribadi yang sudah dibentuk dengan menggunakan algoritma asymmetric. Kode data BMN Polibatam digabungkan dengan hasil enkripsi sebelumnya lalu dibentuklah $Q R$ Code. Sehingga data yang ada di $Q R$ Code bukan kode barang asli akan tetapi berupa "kodeItem, R1", dimana kodeItem berupa barang yang asli dan R1 berupa nilai hasil enkripsi dari nilai hash.

\section{3.) Verify}

$Q R$ Code yang sudah dipindai, akan muncul informasi mengenai kode data BMN Polibatam akan di hash dengan MD-5, sementara itu data enkripsi akan di deskripsi menggunakan kunci public Polibatam sehingga menghasilkan H(M). Hasil hash kode data BMN Polibatam akan diverifikasi dengan nilai hash hasil deskripsi. Apabila nilai hash tersebut sama, maka informasi dari $Q R$ Code tersebut betul dan aplikasi mobile akan menampilkan identitas barang lebih detail. Apabila tidak sama, maka informasi dari $Q R$ Code tersebut diragukan keasliannya dan identitas inventori tidak muncul.

\section{Pengujian Aplikasi}

Pengujian aplikasi pada tahap awal dilakukan dengan metode blackbox testing. Pengujian dilakukan oleh pengembang dan calon pengguna aplikasi, dengan cara mencoba mengoperasikan aplikasi secara fitur dan melihat respon atau luaran yang dihasilkan aplikasi. Hasil pengujian pada Tabel 1, menunjukkan bahwa aplikasi dapat berfungsi sesuai kebutuhan pengguna. 
TABEL I.

Hasil PenguJian FungSiONAL

\begin{tabular}{|c|c|c|c|c|}
\hline No & $\begin{array}{l}\text { Skenario } \\
\text { Pengujian } \\
\end{array}$ & Test Case & $\begin{array}{l}\text { Hasil yang } \\
\text { diharapkan }\end{array}$ & $\begin{array}{l}\text { Hasil } \\
\text { Pengujian }\end{array}$ \\
\hline \multicolumn{5}{|c|}{ Autentikasi pengguna } \\
\hline 1 & $\begin{array}{l}\text { Melakukan } \\
\text { autentikasi } \\
\text { tanpa mengisi } \\
\text { username dan } \\
\text { password }\end{array}$ & $\begin{array}{l}\text { Username: } \\
\text { kosong } \\
\text { Password: } \\
\text { kosong }\end{array}$ & $\begin{array}{l}\text { Sistem } \\
\text { menolak } \\
\text { proses } \\
\text { autentikasi }\end{array}$ & Valid \\
\hline 2 & $\begin{array}{l}\text { Melakukan } \\
\text { autentikasi } \\
\text { dengan user } \\
\text { yang tidak } \\
\text { terdaftar }\end{array}$ & $\begin{array}{l}\text { Username : ad } \\
\text { Password: ad }\end{array}$ & $\begin{array}{l}\text { Sistem } \\
\text { menolak } \\
\text { proses } \\
\text { autentikasi }\end{array}$ & Valid \\
\hline 3 & $\begin{array}{l}\text { Melakukan } \\
\text { autentikasi } \\
\text { dengan user } \\
\text { yang terdaftar }\end{array}$ & $\begin{array}{l}\text { Username: } \\
\text { bmn@polibat } \\
\text { am } \\
\text { Password: } \\
\text { user }\end{array}$ & $\begin{array}{l}\text { User masuk } \\
\text { ke sistem dan } \\
\text { menampilkan } \\
\text { halaman } \\
\text { utama }\end{array}$ & Valid \\
\hline \multicolumn{5}{|c|}{ Menu Utama } \\
\hline 1 & $\begin{array}{l}\text { Menampilkan } \\
\text { home yang } \\
\text { berisi daftar } \\
\text { barang milik } \\
\text { negara }\end{array}$ & $\begin{array}{l}\text { Klik menu } \\
\text { home }\end{array}$ & $\begin{array}{l}\text { Sistem } \\
\text { menampilkan } \\
\text { daftar barang } \\
\text { milik negara }\end{array}$ & Valid \\
\hline 2 & $\begin{array}{l}\text { Memilih barang } \\
\text { milik negara }\end{array}$ & $\begin{array}{l}\text { Klik salah } \\
\text { satu item } \\
\text { barang } \\
\end{array}$ & $\begin{array}{l}\text { Sistem } \\
\text { menampilkan } \\
\text { detail barang }\end{array}$ & Valid \\
\hline 3 & $\begin{array}{l}\text { Mengubah data } \\
\text { barang }\end{array}$ & $\begin{array}{l}\text { Klik edit } \\
\text { barang, input } \\
\text { perubahan }\end{array}$ & $\begin{array}{l}\text { Data barang } \\
\text { berubah }\end{array}$ & valid \\
\hline 4 & $\begin{array}{l}\text { Merubah posisi } \\
\text { barang }\end{array}$ & $\begin{array}{l}\text { Scan QR } \\
\text { Barang, edit } \\
\text { lokasi }\end{array}$ & $\begin{array}{l}\text { Data barang } \\
\text { terdeteksi, } \\
\text { lokasi } \\
\text { berubah }\end{array}$ & Valid \\
\hline 5 & $\begin{array}{l}\text { Menghasilkan } \\
\text { QR }\end{array}$ & $\begin{array}{l}\text { Pilih menu } \\
\text { tambah barang }\end{array}$ & $\begin{array}{l}\text { QR Code } \\
\text { dibuat }\end{array}$ & valid \\
\hline 6 & $\begin{array}{l}\text { Menambah data } \\
\text { barang }\end{array}$ & $\begin{array}{l}\text { QR Code } \\
\text { sudah dibuat, } \\
\text { data barang } \\
\text { diisi }\end{array}$ & $\begin{array}{l}\text { Data barang } \\
\text { tersimpan, } \\
\text { QR dikirim } \\
\text { ke mesin } \\
\text { pencetak }\end{array}$ & Valid \\
\hline 7 & Scan barang & $\begin{array}{l}\text { Klik menu } \\
\text { scan }\end{array}$ & $\begin{array}{l}\text { Aplikasi } \\
\text { membuka } \\
\text { kamera }\end{array}$ & Valid \\
\hline 8 & Scan barang & $\begin{array}{l}\text { Aplikasi } \\
\text { membuka } \\
\text { kamera } \\
\text { diarahkan ke } \\
\text { QR }\end{array}$ & $\begin{array}{l}\text { Aplikasi } \\
\text { mendeteksi } \\
\text { dan verifikasi } \\
\text { QR dan } \\
\text { menampilkan } \\
\text { data barang } \\
\text { yang relevan }\end{array}$ & Valid \\
\hline
\end{tabular}

\section{KESIMPULAN}

Sistem pendataan BMN dengan secure $Q R$ Code dan REST API telah dibangun melalui sebuah prototipe. Prototipe ini dibangun dengan mengintegrasikan aplikasi Mobile QR Code, secured API $Q R$ Code Generator, dan REST API. Aplikasi Mobile $Q R$ Code dapat membaca $Q R$ Code yang ada dan membandingkan dengan data yang ada pada database; Secure $Q R$ Code memberikan layanan keamanan informasi QR terhadap identitas/informasi BMN Polibatam; dan REST API membantu dalam mengelola data BMN.

$Q R$ Code yang dihasilkan tidak menginterpretasikan informasi/identitas BMN melainkan data digital signature BMN. Data digital signature BMN ini berupa data yang khusus sehingga $Q R$ Code BMN Polibatam tidak tercemar dari pemalsuan $Q R$ Code yang ada.

\section{UCAPAN TERIMA KASIH}

Terima kasih kepada Politeknik Negeri Batam yang sudah membantu dalam mendanai penelitian ini melalui skema Penelitian Internal Polibatam 2019

\section{DAFTAR PUSTAKA}

[1] R. Mamin, S. Saenab and N. H. Muhiddin, "Inventarisasi Alat dan Bahan Laboratorium IPA dengan FItur Quick Reponse Code ( $Q R$ Code)," Jurnal IPA Terpadu, pp. 94-105, 2017.

[2] A. P. Atmaja and F. Susanto, "Optimasi Aplikasi SIMAK-BMN untuk Inventarisasi Barang Milik Negara Berbasis Aplikasi Mobile Android," Jurnal Teknologi Informasi dan Ilmu Komputer, vol. 6, pp. 201-210, 2019.

[3] M. Pramihapsari and M. P. Kaldera, "Perancangan Labelling pada Dokumen Menggunakan $Q R$ Code," Jurnal Teknik Komputer, vol. 20 pp. $59-67,2012$

[4] M. A. Rahman, I. Kuswardayan and R. R. Hariadi, "Perancangan dan Implementasi RESTful Web Service untuk Game Sosial Food Merchan Saga pada Perangkat Android," Jurnal Teknik Pomits, vol. 2, pp. 23019271, 2013

[5] "QRcode," Denso Wave Incorporated, 2019. [Online]. Available: https://www.qrcode.com/en/index.html.

[6] R. Munir, Kriptografi, Bandung: Penerbit Informatika, 2019

[7] RI, Peraturan Pemerinta No.27, 2014.

[8] A. Rulloh, D. Mahmudah and H. Kabetta, "Implementasi REST API pada Aplikasi Panduan Kepaskibraan Berbasis Android," Teknikom vol. 1, 2017.

[9] T. Talk, "System Development Life Cycle (SDLC) Approaches," TechTalk, 2015. [Online]. Available: https://techtalk.org/2015/01/21/system-development-life-cycle-sdlc-approaches/.

[10] K. Yusuf, "Penerapan Algoritma MD5 sebagai Pengaman Akun pada Aplikasi Web Emusrenbang Kota Binjai", Jurnal Tekni Informatika Kaputama, vol 4, 2020

[11] D. E. Kurniawan, I. Muslim, M. Raihan, A. P. Putra, and P. A. Yusuf, Mobile Programming: Praktik Membuat Aplikasi Berbasis QR Code dan NFC. Media Sains Indonesia, 2020.

[12] Rusdianto, A.Qhoslim "Implementasi Algoritma MD5 untuk Keamanan Dokumen", Jurnal Ilmiah Ilmu Komputer, vol 2, 2016. 